\title{
A CO-INTEGRATION APPROACH TO FORECASTING FREIGHT RATES IN THE DRY BULK SHIPPING SECTOR
}

\author{
ALBERT WILLEM VEENSTRA \\ Department of Regional Transport and Port Economics, Erasmus University, Rotterdam, The Netherlands
}

and

PHILIP HANS FRANSES

Department of Econometrics and Rotterdam Institute for Business Economics Studies, Erasmus University, Rotterdam, The Netherlands

(Received 8 December 1995; in revised form 25 November 1996)

\begin{abstract}
In this paper, a vector autoregressive model is developed for a sample of ocean dry bulk freight rates. Although the series of freight rates are themselves found to be non-stationary, thus precluding the usc of many modelling methodologies, evidence provided by cointegration tests points to the existence of stable long-term relationships between the series. An assessment of the forecasts derived from the model suggests that the specification of these long-term relationships does not improve the accuracy of short- or long-term forecasts. These results are interpreted as a corroboration of the efficient market hypothesis. (C) 1997 Elsevier Science Ltd
\end{abstract}

\section{INTRODUCTION}

Freight rates have been a topic of interest in the shipping industry for a long time. Due to the ongoing uncertainty in international shipping and especially the volatile nature of freight rates, members of the shipping community have always expressed a strong interest in quantitative analyses of freight rates. Some evidence of this claim can be found in the large and ever-growing body of literature on pricing models in shipping, in the abundance of freight rate data that is made available to the shipping industry and in the existence of various software packages that produce freight rate forecasts. A notable example of such a package is the so-called 'Freight Forecaster', developed by Maritime Stratcgics International Ltd in the United Kingdom. Until recently, the quantitative approach mainly consisted of attempts to model freight rates and other variables of interest together with their determinants in linear regression systems; for some examples, see Hawdon (1978), Strandeness (1986) and Beenstock and Vergottis (1993). An exception is Cullinane (1992), where the Box-Jenkins methology is applied to generate forecasts in dry bulk shipping.

This paper presents a relatively new approach to modelling freight rates in shipping, an approach which uses only the freight rate data themselves. In other words, we consider a multivariate time series model. The intention is to build a model for freight rates that is meaningful in terms of established microeconomic theory. The model development is preceded by a descriptive analysis of the univariate data to examine the overall structure of shipping freight rates.

The main justification for modelling freight rates in a multivariate time series model is that shipping markets are assumed to be approximately efficient. In fact, the conditions for perfect and competitive markets all hold to a considerable extent in shipping [see, for instance, Evans (1994)], since aspects that might disturb efficiency in perfectly competitive markets like externalities and informational asymmetry are resolved in one way or another. For instance, informational asymmetry, i.e. the situation where one contract partner has less information than another partner, may emerge in the shipping operation. However, the charter party, the transportation contract between a charterer and a shipowner, solves many such information gaps by accurately specifying the speed of the ship, the number of days allowed for loading and unloading, the consumption of fuel, the payments that have to be made if the ship is late or early and so forth. 
Assuming that the market is efficient, it can be argued that the relevant freight rates contain all publicly available information; see Fama (1970) for the various forms of market efficiency and Nicholson $(1989$, p. 258$)$ on market efficiency in general. Thus, in that case, no extra variables beyond freight rates are necessary for model building. Given the obvious linkage of freight rates over time, one might expect that the freight rates of different parts of the shipping industry are correlated. One can try to identify the underlying structure which can be summarized in a multivariate time series model for a set of freight rates. The resulting model can then serve two purposes. The first is to generate forecasts, the second is to identify the long-term trend behind the freight rates. In this paper we pursue both purposes. A third purpose of our paper is to investigate whether our multivariate time series model outperforms the no-change forecasting model. If not, we may feel confident with the efficient market hypothesis for our freight rates.

The structure of this paper is as follows. The next section presents the testing techniques that are used to analyze the freight rates; i.e. stationarity and cointegration tests. In this section we also describe the data and present the estimation results. The next section contains the results that concern the stochastic trend, which we estimate from the data. In the next section, we forecast freight rates using the obtained structure. The next section presents the evaluations of the forecasts. In the final section conclusions are drawn. All calculations concerning estimation and data analysis (including the cointegration tests) are performed through standard options in Eviews-TSP for Windows, version 1.0. Forecasts and stochastic trend calculations are performed using some routines in the matrix language Gauss, version 3.1.

\section{DATA ANALYSIS}

As is usual in applied economic time series modelling, the data analysis consists of several parts. First we describe and plot the data. From the graphs, one can obtain a first indication of the structure in the data. Second, a univariate time series analysis is performed using formal statistical techniques. This analysis provides information on unit roots and the general dynamic structure of the individual series. Having arrived at this point, a multivariate model can be hypothesized. Subsequently, the parameters in this model are estimated.

\section{Data analysis of the univariate series}

The data were kindly made available by Clarkson Research Studies Ltd in the United Kingdom, a company that collects, processes and maintains much data on the shipping industry, including an extensive number of freight rate series over a large span of time. We use their database of dry bulk freight rates. As with all other sources of freight rate data, during the late eighties, Clarksons made some changes to the reported freight rate series. This was due to larger ships being more regularly used on certain routes, some unreported routes becoming more important and trade declining on some of the reported routes. These changes in reported freight rate series make it difficult, although not impossible, to obtain data series that stretch over 15 or more years. Series that were reported before and after the period in which changes were made can sometimes be adequately combined into longer series. In the Clarkson database this was possible with the series presented in Table 1. Further details on the construction of the data can be obtained from the corresponding author. In this paper we analyze the data after taking natural logarithms. This overcomes comparability problems in the data, since the series originate from quite different sections of the dry bulk shipping industry. Taking logarithms also stabilizes the variances of the series, and reduces the impact of heteroscedasticity. For ease of reference, the first three series in Table 1 are termed the 'Capesize series' and the second three are termed the 'Panamax series'. The Capesize and Panamax variables are plotted in Figs 1 and 2, respectively.

The striking feature of these graphs is that the patterns of the series seem similar. This feature by itself justifies that there may be some economic structure that ties the series together. In order not to complicate the analysis, we assume that this structure is linear.

The strength of the relationship between the series is further established through the correlations presented in Table 2. From this table, we also observe that the mean values are equally spaced within the two size groups and the standard deviations are quite alike.

The sample for the six series defined in Table 1 covers the period September 1983 to February 1995. In order to save actual observations for an ex-ante evaluation of forecasting performance, 
Table 1. Description of series used in the analysis

\begin{tabular}{|c|c|c|c|}
\hline \multirow[b]{2}{*}{ Route cargo } & \multicolumn{2}{|c|}{ Size } & \multirow[b]{2}{*}{ Series name } \\
\hline & Old & New & \\
\hline \multicolumn{4}{|l|}{ The Capesize series } \\
\hline $\begin{array}{l}\text { 1. Tubarao-Rotterdam } \\
\text { iron ore }\end{array}$ & $\begin{array}{l}80000 \mathrm{dwt}^{b} \\
\text { (before } 1988 \text { ) }\end{array}$ & $\begin{array}{l}145000 \mathrm{dwt} \\
\text { (after 1988) }\end{array}$ & Y1CAP \\
\hline $\begin{array}{l}\text { 2. Tubaroa-Japan } \\
\text { iron ore }\end{array}$ & $\begin{array}{c}130000 \mathrm{dwt} \\
\text { (before } 1989 \text { ) }\end{array}$ & $\begin{array}{l}145000 \mathrm{dwt} \\
\text { (after 1989) }\end{array}$ & Y2CAP \\
\hline $\begin{array}{l}\text { 3. Hampton Roads/Richards Bay-Japan } \\
\text { coal }\end{array}$ & $\begin{array}{l}100000 \mathrm{dwt} \\
\text { (before 1989) }\end{array}$ & $\begin{array}{l}132000 \mathrm{dwt} \\
\text { (after 1989) }\end{array}$ & Y3CAP \\
\hline \multicolumn{4}{|l|}{ The Panamax seriesa } \\
\hline $\begin{array}{l}\text { 4. Roberts Bank-Japan } \\
\text { coal }\end{array}$ & $\begin{array}{c}50000 \mathrm{dwt} \\
\text { (before 1989) }\end{array}$ & $\begin{array}{l}64000 \mathrm{dwt} \\
\text { (after 1989) }\end{array}$ & Y4PAN \\
\hline $\begin{array}{l}\text { 5. US Gulf-Rotterdam } \\
\text { grain }\end{array}$ & $\begin{array}{c}50000 \mathrm{dwt} \\
\text { (before 1989) }\end{array}$ & $\begin{array}{l}54500 \mathrm{dwt} \\
\text { (after 1989) }\end{array}$ & YSPAN \\
\hline $\begin{array}{l}\text { 6. Hampton Roads-Rotterdam } \\
\text { coal }\end{array}$ & $\begin{array}{c}50000 \mathrm{dwt} \\
\text { (before 1989) }\end{array}$ & $\begin{array}{l}122000 \mathrm{dwt} \\
\text { (after 1989) }\end{array}$ & Y6PAN \\
\hline
\end{tabular}

'The terms 'Capesize' and 'Panamax' used here, are the same as the terms used to describe ships of a certain size range in the dry bulk shipping industry.

bDead weight ton.

cThe full description of this route is Hampton Roads (U.S. West Coast)/Richards Bay (South Africa)-Japan.

This route changes from a Panamax to a Capesize route after 1989.

we set the estimation sample for the model to cover the shorter period of September 1983 to August 1993, yielding a sample of 120 monthly observations.

Testing for unit roots in univariate time series has become a standard tool in modern econometric data analysis. Since conventional statistical analysis assumes that the time series at hand are stationary, and since a unit root implies non-stationarity (see Mills, 1990), it is important to test for unit root. Stationarity implies that the theoretical mean and variance of a time series process are constant over time and that the autocovariances and autocorrelations only depend on the time difference between the observations involved, see Mills $(1990$, p. 64.) One type of non-stationarity is the so-called unit root non-stationarity. This type of non-stationarity can be established through a formal test on the presence of a unit root in the series. Testing for unit roots enables direct inference on the degree of non-stationarity and the subsequent degree of differencing to transform a time series to stationarity. Several tests are available in the literature. In this study, we restrict our attention to the augmented Dickey-Fuller (DF) test, since it is widely applied (see Mills, 1990 for details and Dickey and Fuller, 1979 for the original derivation). The null hypothesis for the DF test is that a time series is non-stationary with a unit root, possibly with a non-zero growth rate or drift.

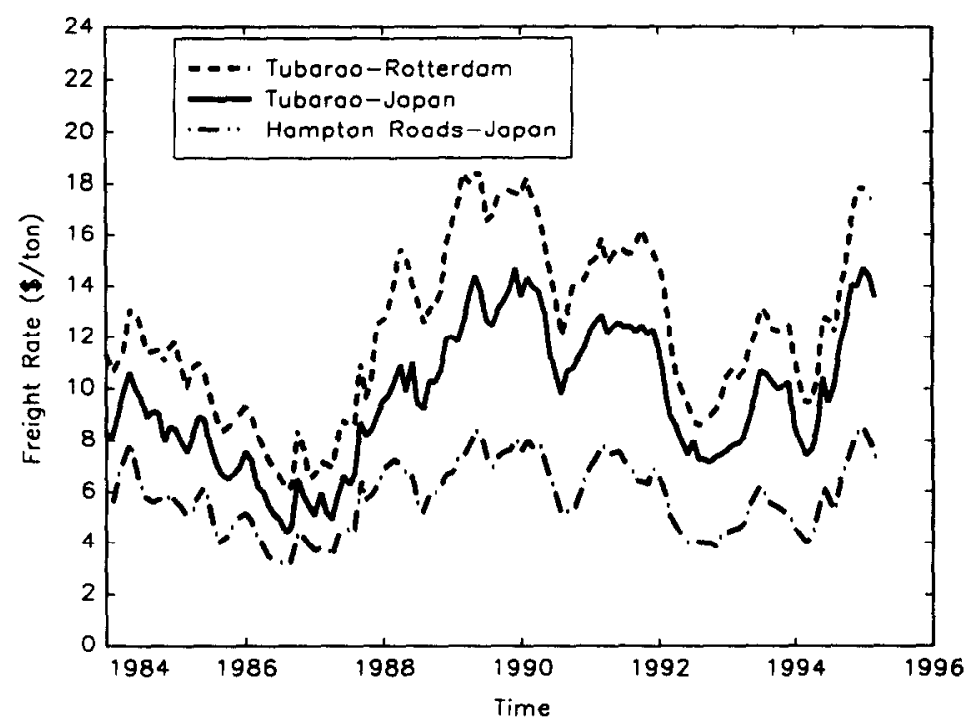

Fig. 1. Capesize series. 


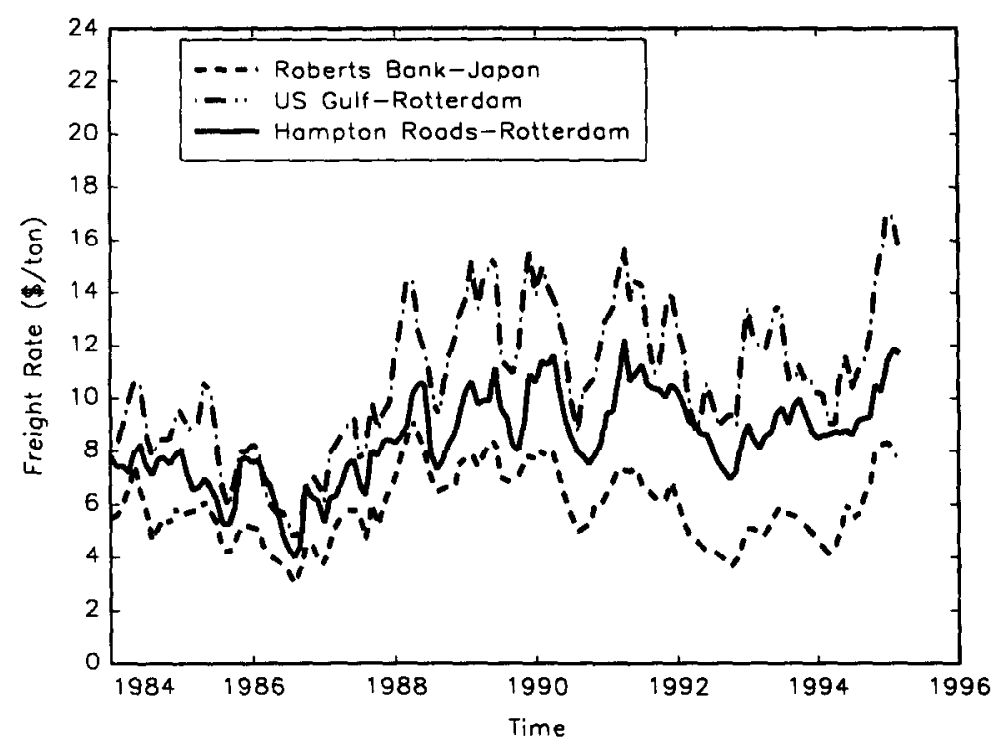

Fig. 2. Panamax series.

Table 2. Correlations ${ }^{a}$. Series in logarithms

\begin{tabular}{lcccccccc}
\hline & Y1CAP & Y2CAP & Y3CAP & Y4PAN & Y5PAN & Y6PAN & MEAN & s.d. \\
\hline Y1CAP & 1.00 & 0.98 & 0.93 & 0.87 & 0.87 & 0.85 & 2.47 & 0.28 \\
Y2CAP & & 1.00 & 0.92 & 0.83 & 0.87 & 0.85 & 2.22 & 0.29 \\
Y3CAP & & & 1.00 & 0.92 & 0.82 & 0.78 & 1.72 & 0.25 \\
Y4PAN & & & & 1.00 & 0.82 & 0.75 & 1.74 & 0.23 \\
YSPAN & & & & & 1.00 & 0.91 & 2.11 & 0.21 \\
Y6PAN & & & & & & 1.00 & 2.33 & 0.27 \\
\hline
\end{tabular}

${ }^{a}$ Estimation sample is September 1983-August 1993 (120 observations).

The results from Table 3 show that all series are non-stationary at the $1 \%$ level, and that two series seem stationary at the $5 \%$ level. For further analysis, assume, however, that all six univariate series have a unit root.

\section{Econometric model}

The correlations, the unit root test results and the graphs in the previous tables and figures are all evidence that the series may have common properties. A straightforward way of describing these properties is by assuming a multivariate time series model, or vector autoregressive model (VAR) model, that explains the six freight rate series through their own lagged values and which is somehow restricted to reflect the common features. Since the DF tests indicate that the series are all non-stationary, this VAR model may hold for the differences of the series. However, building a VAR model based only on differenced variables is statistically undesirable, since information about possible long-run relationships between the variables is lost (see, for instance, Engle and Granger 1987).

Table 3. Unit root tests results series in logarithms the null hypothesis corresponds to unit-root stationarity, while the alternative hypothesis concerns covariance-stationarity

\begin{tabular}{lcccccc}
\hline Series & Y1CAP & Y2CAP & Y3CAP & Y4PAN & Y5PAN & Y6PAN \\
\hline$t$-statistic & -1.77 & -1.60 & -2.67 & -2.79 & $-2.96^{\circ}$ & $-3.08^{\circ}$ \\
Number of lags & 1 & 0 & 1 & 1 & 1 & 1 \\
\hline
\end{tabular}

andicates that the test statistic is significant at the $S \%$ level and hence that the null hypothesis of a unit root can be rejected. The reported tests are performed in a regression which includes a constant. Critical values for the unit root tests without a trend are $-3.49,-2.89$ and -2.58 for the 1,5 and $10 \%$ level, respectively, see MacKinnon (1991). 'Number of lags' indicates the number of lagged differenced variables that are included in the regression to whiten the errors. The number of lags is decided upon by applying conventional tests for residual correlation. 
Table 4. Unit root test results for the variable $z_{t}=x_{t}-y_{t}$, where $x_{t}$ and $y_{t}$ concern the variables in Table 1 (in logs)

\begin{tabular}{lccccc}
\hline Series & Y2CAP & Y3CAP & Y4PAN & Y5PAN & Y6PAN \\
\hline Y1CAP & -5.56 & -3.28 & -2.63 & -3.68 & -2.79 \\
Y2CAP & & $-2.58^{a}$ & $-2.45^{a}$ & -3.52 & -3.48 \\
Y3CAP & & -3.90 & -4.49 & -2.81 \\
Y4PAN & & & $1.71^{a}$ & 2.69 & -4.92 \\
YSPAN & & & & \\
\hline
\end{tabular}

Indicates that non-stationarity cannot be rejected at the $10 \%$ level. Critical values for the Dickey-Fuller unit root tests with a constant and no trend are $-3.47,-2.88$ and -2.58 for the 1,5 and $10 \%$ level, respectively [see MacKinnon (1991)]. Lags of differenced left-hand side variables were added for the combinations Y4PAN-Y6PAN and Y5PAN-Y6PAN.

There are many possible hypotheses of the underlying long-run relationships between the freight rate series, of which only a few have an economic interpretation. One plausible set of relations would be that all series are related in pairs of two in such a way that the unweighted difference of two series is stationary. This amounts to the assumption that pairs of series are cointegrated (with a unit cointegration vector) (see Engle and Granger 1987). Cointegration implies that although two series are non-stationary, or integrated, such that first differences are required to obtain stationarity, a linear combination of these series can be stationary. Since an unweighted difference between two series $x$ and $y$, i.e. $x-y$, can also be described as the vector product $(1,-1) .(x, y)$, one can call these differences $(1,-1)$ linear combinations. For six series, as in our case, pairwise $(1,-1)$ cointegration would lead to five so-called cointegration relations. To test if these assumptions are in any way reasonable, unit root tests are performed on the unweighted differences between all possible combinations of two out of the six series, a total of 15 possibilities. The unit root test results are presented in Table 4.

The results in Table 4 convincingly show that almost all unweighted differences between any two of the six series are stationary.

Alternative to the above (pairwise) approach, one may also investigate cointegration amongst all six variables in one step. In this paper, we use the test methodology of Johansen (1991) for this purpose. If a cointegration relation between a set of series can be established, the Granger Representation Theorem states that the VAR can be written as a vector error correction (VEC) model, and vice versa [see Engle and Granger (1987) for the original formulation of this theorem]. Thus, the existence of cointegration relations implies that 'disequilibrium errors' are corrected in subsequent periods, and this again indicates that the series are closely linked.

The cointegration test procedure of Johansen is executed by estimating a VEC model, see eqn (1) below. The number of cointegration relations is established by a sequential likelihood ratio test on the rank of an estimated parameter matrix from the VEC model. This rank test is based on the eigenvalues of the parameter matrix. In Table 5 , where the results of the cointegration tests of the six freight rates are reported, we present these eigenvalues together with the likelihood ratio statistic.

The test results in Table 5 seem to indicate the presence of three cointegration relations at the $5 \%$ level. The failure to reject the null hypotheses of three and four cointegration relations may, however, be due to the typical low power of the test statistics in cases where many parameters have

Table 5. Co-integration test results series in logarithms

\begin{tabular}{lrrrrrr}
\hline $\begin{array}{l}\text { Number of co-integration } \\
\text { relations of at most, } n\end{array}$ & 0 & 1 & 2 & 3 & 4 & 5 \\
\hline Likelihood ratio & 123.72 & 80.38 & 49.54 & 25.54 & 8.97 & 2.72 \\
Eigenvalue & 0.30 & 0.23 & 0.18 & 0.13 & 0.05 & 0.02 \\
$1 \%$ critical value & 103.18 & 76.07 & 54.46 & 35.65 & 20.04 & 6.65 \\
$5 \%$ critical value & 94.15 & 68.52 & 47.21 & 29.68 & 15.41 & 3.76 \\
$10 \%$ critical value & 89.48 & 64.84 & 43.95 & 26.79 & 13.33 & 2.69 \\
Tests outcome & $*$ & $*$ & + & & & \\
\hline
\end{tabular}

The null hypothesis of 0 co-integration relations is tested against the alternative hypothesis of at most $n$ co-integration relationships.

* Means that the null hypothesis is rejected at the $1 \%$ level.

+ Means that the null hypothesis is rejected at the $5 \%$ level. The sample period is September 1983-August 1993. Critical values are obtained from Osterwald-Lenum (1992). The test option with a constant, but no trend in the data or the cointegration relation is used. The order of the VAR model is equal to one. The order of the VAR is based on diagnostic tests for residual correlation. 
Table 6. Estimated cointegration parameters in the case of five co-integration relations

\begin{tabular}{|c|c|c|c|c|c|c|c|}
\hline Relation & YICAP & Y2CAP & Y3CAP & Y4PAN & Y5PAN & Y6PAN & $\mathrm{C}$ \\
\hline $\begin{array}{l}1 \\
2 \\
3 \\
4\end{array}$ & 1.00 & 1.00 & 1.00 & 1.00 & 1.00 & $\begin{array}{l}-1.50 \\
-1.54 \\
-1.05 \\
-0.86 \\
-1.36\end{array}$ & $\begin{array}{r}-0.68 \\
-1.01 \\
-0.48 \\
-0.05 \\
-0.53\end{array}$ \\
\hline
\end{tabular}

to be estimated. Given the large values of the test statistics for four and five cointegration relations, we accept that there are five cointegration relations. If we consider five such relations within the VAR model, we obtain the estimated cointegration parameters as presented in Table 6, where the cointegration relations are normalized on the sixth variable, Y6PAN.

Table 6 shows that the cointegration parameters are quite close to unity and, hence, that $(1,-1)$ long-run relationships (which we presumed in Table 4) may indeed be valid. The hypothesis that these cointegrated variables are zero-mean stationary can be tested through a likelihood ratio test. In the cointegration test methodology of Johansen, given our data set and the assumption of five cointegration relations, we estimate the following VEC model:

$$
\left[\begin{array}{c}
\Delta Y 1 C A P_{t} \\
\Delta Y 2 C A P_{t} \\
\Delta Y 3 C A P_{t} \\
\Delta Y 4 P A N_{t} \\
\Delta Y 5 P A N_{t} \\
\Delta Y 6 P A N_{t}
\end{array}\right]=c+[\alpha] \cdot\left[\begin{array}{c}
10000 \theta_{1} c_{1} \\
01000 \theta_{2} c_{2} \\
00100 \theta_{3} c_{3} \\
00010 \theta_{4} c_{4} \\
000001 \theta_{5} c_{5}
\end{array}\right] \cdot\left[\begin{array}{c}
Y 1 C A P_{t-1} \\
Y 2 C A P_{t-1} \\
Y 3 C A P_{t-1} \\
Y 4 P A N_{t-1} \\
Y 5 P A N_{t-1} \\
Y 6 P A N_{t-1} \\
1
\end{array}\right]+\varepsilon_{t}
$$

Here the variables as introduced in Table 1 are extended with a time index, $\Delta$ is the first differencing filter, $c$ is a $(6 \times 1)$ vector of constants, $\varepsilon_{l}$ is a $(6 \times 1)$ vector of white noise residuals, $\alpha$ is a $(6 \times 5)$ matrix of so-called adjustment parameters, $\theta_{i}$ are the cointegration parameters in Table 6 and $c_{i}$ are the constants in the cointegration relation $(i=1,2,3,4,5)$. The explanatory variables on the right hand side of the model are stationary, as previously shown in Table 5 . The likelihood ratio test of the model in (1) with the restrictions $\theta_{i}=1$ and $c_{i}=0$; versus an unrestricted VEC model with five cointegration restrictions obtains a value of 15.6. Comparing this with fractiles of the $\mathrm{X}^{2}(10)$ distribution, it is clear that we cannot reject our hypothesis at the $5 \%$ level.

\section{Final Estimation results}

When we estimate the parameters in the VEC model by ordinary least squares, we obtain

$$
\begin{aligned}
& {\left[\begin{array}{l}
\Delta Y 1 C A P_{t} \\
\Delta Y 2 C A P_{t} \\
\Delta Y 3 C A P_{t} \\
\Delta Y 4 P A N_{t} \\
\Delta Y 5 P A N_{t} \\
\Delta Y 6 P A N_{t}
\end{array}\right]=\left[\begin{array}{r}
0.08 \\
-0.08 \\
-0.07 \\
-0.02 \\
0.00 \\
0.02
\end{array}\right]+\left[\begin{array}{rrrrr}
-0.24 & 0.13 & -0.03 & 0.14 & -0.14 \\
0.33 & -0.42 & 0.07 & -0.01 & 0.14 \\
0.10 & -0.04 & -0.22 & 0.18 & 0.08 \\
0.06 & -0.10 & 0.09 & -0.07 & -0.09 \\
0.05 & 0.08 & -0.09 & 0.10 & -0.11 \\
-0.06 & 0.07 & 0.03 & 0.07 & -0.15
\end{array}\right] } \\
& \times\left[\begin{array}{r}
10000-1 \\
01000-1 \\
00100-1 \\
00010-1 \\
00001-1
\end{array}\right] \cdot\left[\begin{array}{r}
Y 1 C A P_{t-1} \\
Y 2 C A P_{t-1} \\
Y 3 C A P_{t-1} \\
Y 4 P A N_{t-1} \\
Y 5 P A N_{t-1} \\
Y 6 P A N_{t-1}
\end{array}\right]
\end{aligned}
$$

Coefficients that are significantly different from zero are indicated in bold. 
We find that only four adjustment coefficients (in $\alpha$ ) are significantly different from zero. In our forecasting exercise, we set all other parameters to zero.

\section{THE COMMON STOCHASTIC TREND}

A phenomenon that can often be observed when modelling ocean freight rates (see in our case Figs 1 and 2), is that different freight rates exhibit quite similar patterns. This similarity may indicate the existence of a common drive or common stochastic trend, that forms the basis of the freight rates in shipping and may determine the general pattern of freight rates.

A condition for one common trend to exist for six freight rates is that there are five cointegration relations in the set of freight rates [see Johansen (1991)]. To find an expression for the stochastic trend, and to discover a way of calculating that trend, we consider again the VEC specification of our VAR(1) model, which can be summarized as

$$
\Delta Y_{t}=c+\alpha \beta^{\prime} Y_{t-1}+\varepsilon_{t}
$$

Here $Y_{t}$ is a vector of $n$ series, in our case Y1CAP, Y2CAP, Y3CAP, Y4PAN, Y5PAN and Y6PAN, $c$ is a vector of constants, $\alpha$ and $\beta$ are $n \times r$ matrices, where $r$ is the rank of these matrices, and $\varepsilon_{\mathrm{t}}$ is the error term. Notice that $n=6$ and $r=5$ in our application. In this model, the relationships $\beta^{\prime} Y_{t-i}$ (i.e. the cointegration relations) define the underlying economic relationships. We can now define full rank matrices $\alpha_{\perp}$ and $\beta_{\perp}$ of dimensions $n \times(n-r)$, which form the solution to $\alpha^{\prime} \alpha_{\perp}=0$ and $\beta^{\prime} \beta_{\perp}=0$. If the matrix $\alpha_{\perp}^{\prime} \beta_{\perp}$ also has full rank, then (3) can be solved as

$$
Y_{t}=Y_{0}+M c t+M \sum_{i} \varepsilon_{i}+X_{t}
$$

with

$$
M=\beta_{\perp}\left(\alpha_{\perp}^{\prime} \beta_{\perp}\right)^{-1} \alpha_{\perp}^{\prime}
$$

and $Y_{0}$ is some initial value, and $X_{t}$ is a stationary series.

The structure of the coefficient matrix $M$ is such that the cumulative effect of all shocks to the system is given by $\alpha_{\perp}^{\prime} \sum \varepsilon$. Indeed, multiplying both sides of eqn (4) with $\alpha_{\perp}^{\prime}$ gives the required expression. This expression is defined in Johansen (1994) as the set of common trends. In case of a VAR(1) with one common trend, we can represent this trend simply by $\alpha_{\perp}^{\prime} Y_{t}$.

For our empirical exercise, we have the $\alpha$ matrix as in (2). To obtain the stochastic trend, we calculate $\alpha_{\perp}$ and multiply it with $Y_{t}$. The $\alpha_{\perp}$ for eqn (2) is: $(-0.308,-0.188,0.382,0.230,-0.543$, 0.613 ). In Fig. 3, we depict the underlying stochastic trend driving our six series.

The stochastic trend is unforecastable, since by definition it is a random walk process. It simply portrays the unexplained part of the data when deterministic or common relationships in the data set have been removed. From Fig. 3 it seems, that the stochastic trend contains an irregular cyclical pattern over the years, which may be generated by random economic events in the world economy such as wars and oil crises. In addition, we observe an upward swing in 1994/1995. When we analyse data before that period and we try to forecast this swing, we cannot expect a successful forecast record. On the other hand, we find considerable deterministic relationships (i.e. cointegration) in the data set. These deterministic relationships could help in forecasting changes in freight rates over a short- to medium-term period. This will be pursued in the next section.

\section{FORECASTING}

A forecasting equation can easily be derived on the basis of the general model in eqn (3). To derive a forecasting equation for the variable $Y_{t}$ (as compared to the variable $\Delta Y_{t}$ ), we write eqn (3) as:

$$
Y_{t+1}=c+\left(I+\alpha \beta^{\prime}\right) Y_{t}+\varepsilon_{t+1}
$$




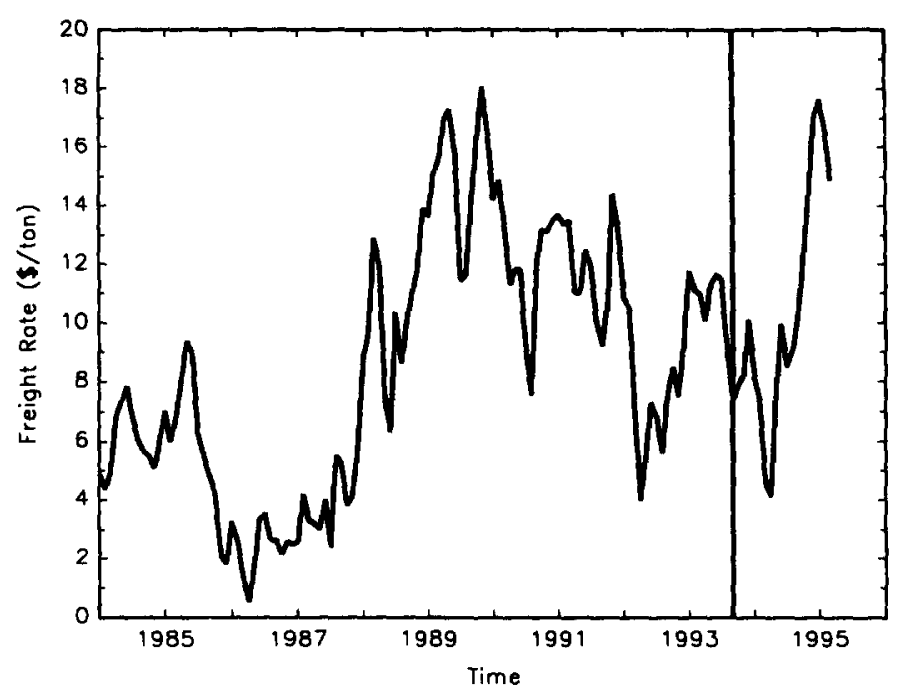

Fig. 3. Stochastic trend.

where $I$ is a $(6 \times 6)$ identity matrix. Since forecasts for $\varepsilon_{\mathrm{t}+\mathrm{h}}$ equal zero, the general expression for an $h$-step ahead forecast is:

$$
Y_{t+h}=A^{h} Y_{t}
$$

where the expression $\left(I+\alpha \beta^{\prime}\right)$ in (6) is replaced by $A$. In eqn (7), the vector of constants is ignored, because some preliminary (but unreported) calculations of forecasts showed that the constants dominate the forecasts very quickly. This is undesirable, especially because most of the constants are not significantly different from zero. Standard errors for the forecasts calculated with eqn (7) can be obtained by taking the square root from the diagonal elements of the covariance matrix of the forecast errors. This covariance matrix can be calculated using the estimated values in the matrix $\mathrm{A}$, according to the following formula:

$$
\sum_{f}(h)=\sum_{i=0}^{h-1} A^{i} \sum_{\varepsilon} A^{i^{\prime}}
$$

[see Mills (1990)] where $\sum_{f}(h)$ is the covariance matrix of the $h$-th step forecast and $\sum_{\varepsilon}$ the covariance matrix of the residuals of the forecasting model. With these standard errors, $95 \%$ confidence bounds for the forecasts can be computed.

To obtain a proper forecast, the matrix A should contain only those coefficients in $\alpha$ that can reasonably contribute to the forecasts. Thus, the forecast model is different from the estimated model in eqn (2). The procedure to obtain the sparser forecasting model is to set insignificant coefficients equal to zero step by step. This procedure is followed until as many coefficients as possible are set to zero while, at the same time, as many coefficients that contribute considerably are retained. These last coefficients are mostly those with the larger coefficient values. Thus, the forecasting model may contain some coefficients that were insignificant in eqn (2) but are signifcant in the forecasting model. We justify our simplified model by calculating likelihood ratio tests to jointly test all zero restrictions.

Our final forecasting model has the same structure as eqn (2). After stepwise simplification we find that the elements of $\alpha$ are estimated as

$$
\left[\begin{array}{lllll}
-0.12 & 0 & 0 & 0.10 & 0.15 \\
0.34 & -0.39 & 0 & 0 & 0.14 \\
0 & 0 & -0.18 & 0.18 & \underline{0.10} \\
0 & 0 & 0 & 0 & \underline{0.08} \\
\underline{0.08} & 0 & 0 & 0 & 0 \\
0 & 0 & 0 & 0 & 0.19
\end{array}\right]
$$


The underlined coefficients in eqn (9) are actually not significantly different from zero. However, observing the size of the estimated parameters, the model may be able to improve upon a naive forecasting strategy, especially for the first two or three series, since the equations corresponding to these variables contain several relevant non-zero coefficients. A likelihood ratio test of the hypothesis that 18 of the 30 coefficients in $\alpha$ in the model in eqn (2) could indeed be set equal to zero [as we do in eqn (9)], gives an LR value of 24.88 . This statistic does not exceed the $5 \%$ critical value of the $\chi^{2}(18)$ distribution. The model with the $\alpha$-matrix as in (9) is the smallest forecasting model that can be statistically justified. Deleting one more (insignificant) variable immediately leads to a rejection of the joint hypothesis that 19 coefficients can be set equal to zero.

Forecasts for the period September 1993 to February 1995 can be generated in several different manners. We confine ourselves to dynamic forecasts for 1 up to 18 periods ahead (in the sense that forecasts are generated using previous period forecasts as inputs) and to forecasts for 1 period ahead for the each of the 18 periods. These forecasts will be compared with the naive forecasting method where the observation in the previous period is used as a forecast. The actual observations for the six series serve as a basis for the forecasting errors. The forecasts produced by the dynamic forecasting method (where we transform the forecasting values back to levels by taking exponentials) are presented in Figs 4 and 5.

\section{EVALUATION OF FORECASTS}

The forecasts in Figs 4(a)-(c) and 5(a)-(c) do not seem to pick up the actual freight rate movements. On the other hand, we observe that the realized observations are usually well within the $95 \%$ forecasting intervals. A normal feature of VAR models is that the longer term forecasts tend towards the estimated average of the series in the model, and this can also be observed from the graphs in Figs 4 and 5 . Another reason why the model may not perform well in the long term is illustrated by the stochastic trend in Fig. 3. This trend shows a steady increase in freight rates in the forecasting sample.

In Table 7, forecasting evaluation criteria for the dynamic method and the one-period method are presented. Forecasting errors are averaged over the applicable number of periods. For the dynamic method, this means that the average errors are calculated for eighteen forecasts ranging from one to eighteen periods ahead. For the one-period forecasts, the averages are calculated over eighteen single period forecasts. On the basis of the information in Table 7, it is clear that our proposed multivariate VEC model with 5 cointegration relations is defeated by a naive forecasting strategy for both the short and long term forecasts.

\section{CONCLUSIONS}

In this paper, a model has been proposed that represents the structure between a number of ocean bulk freight rate series. Statistical examination of the series has led to evidence of non-stationarity and cointegration relations between the series. Based on formal statistical tests, we assumed that there are five cointegration relations between the six series and we formulated a VEC model. This model has the attractive feature that the first differences of the six freight rate series are explained by simple differences between the freight rate series. On the basis of this model, we formulated two applications; an estimation of the underlying stochastic trend and the calculation of forecasts for the freight rate series. The stochastic trend proved to be quite similar to all six series. This means that a large part of the general pattern of the freight rate series is stochastic in nature and therefore cannot be forecasted. This result was further strengthened by the second application. It proved to be difficult to obtain reliable forecasts with the proposed model.

The results presented in this paper indicate that an economically meaningful structure exists in a set of ocean dry bulk freight rates; that is, there are stable long-run relationships between such freight rates. On the basis of this structure, the stochastic trend behind the freight rates can be uncovered. It turns out that a substantial part of the movement in freight rates is stochastic in nature. Our results do not seem to be in conflict with the efficient market hypothesis as it applies to ocean freight rates. Even though there appear to be long-run relationships between freight rates, we find that such relationships do not result in improved forecasts.

Whether our results are due to the fact that we only consider time series models, i.e. models without exogenous explanatory variables, is left for further research. 
(a)

Tuboroo-Rotterdam

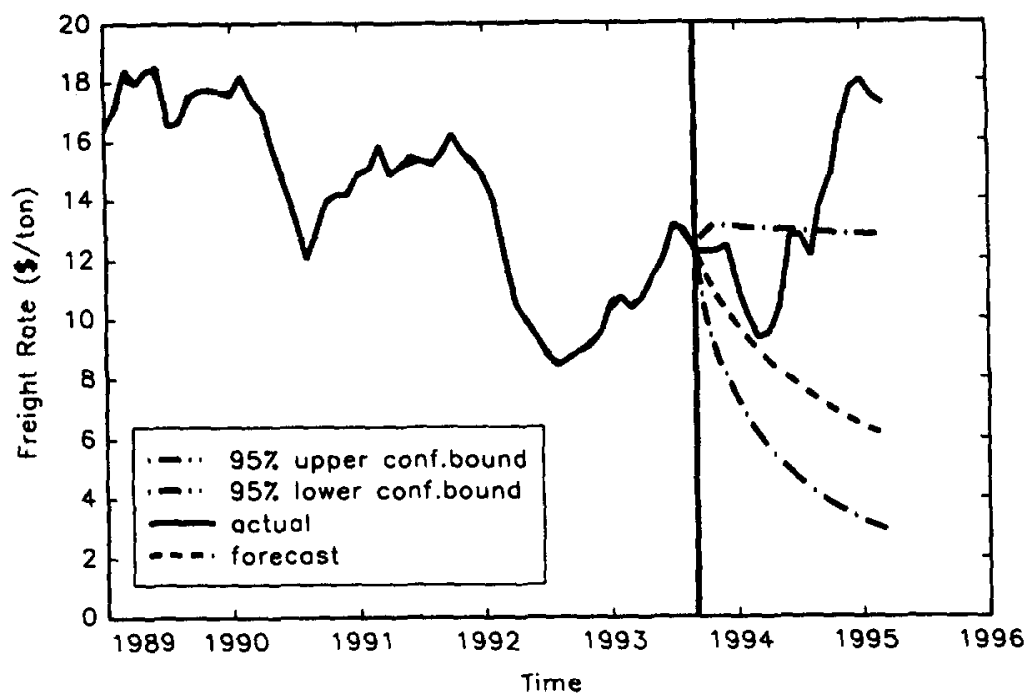

(b)

Tuborao-Japan

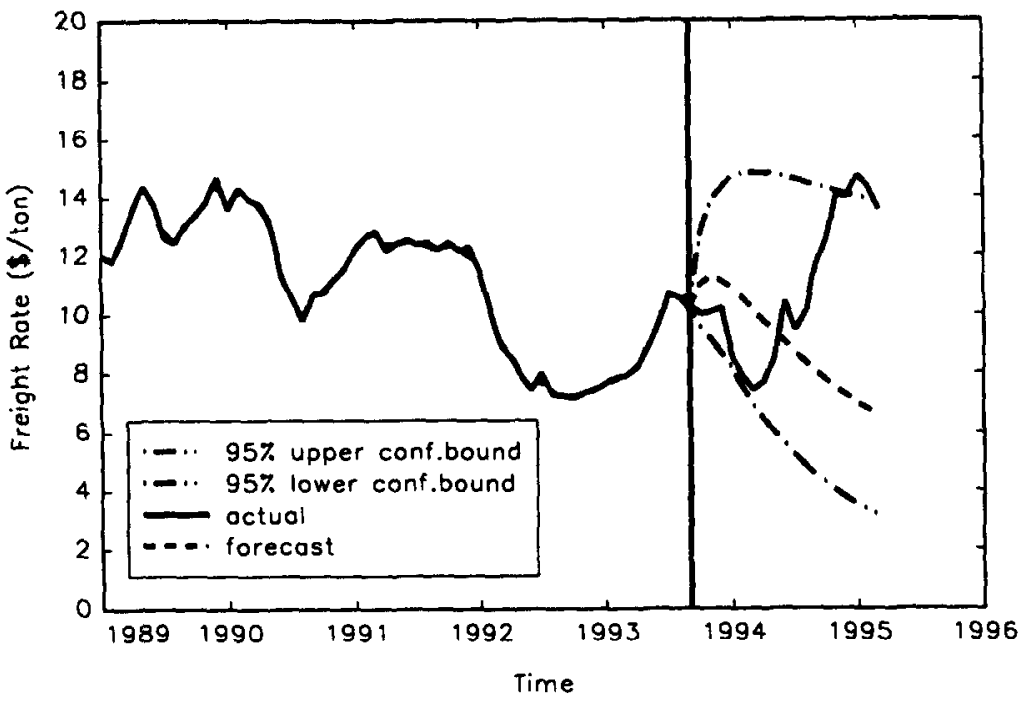

(c)

Hampton Roads-Japan

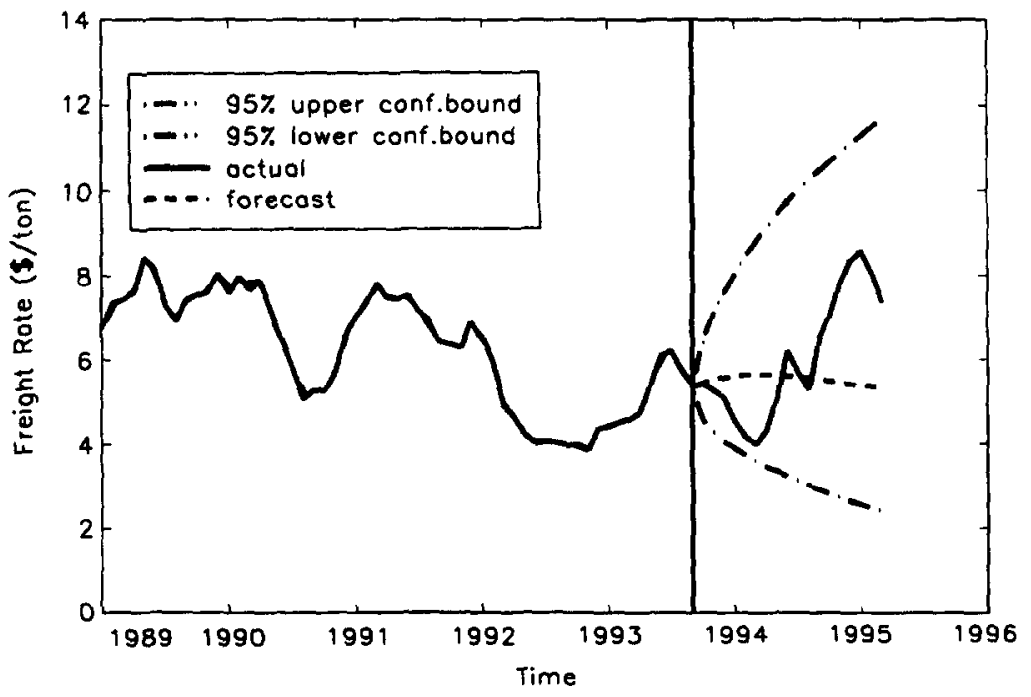

Fig. 4. Capesize series, forecasts and actual series. 
(a)

Roberts Bank-Jopon

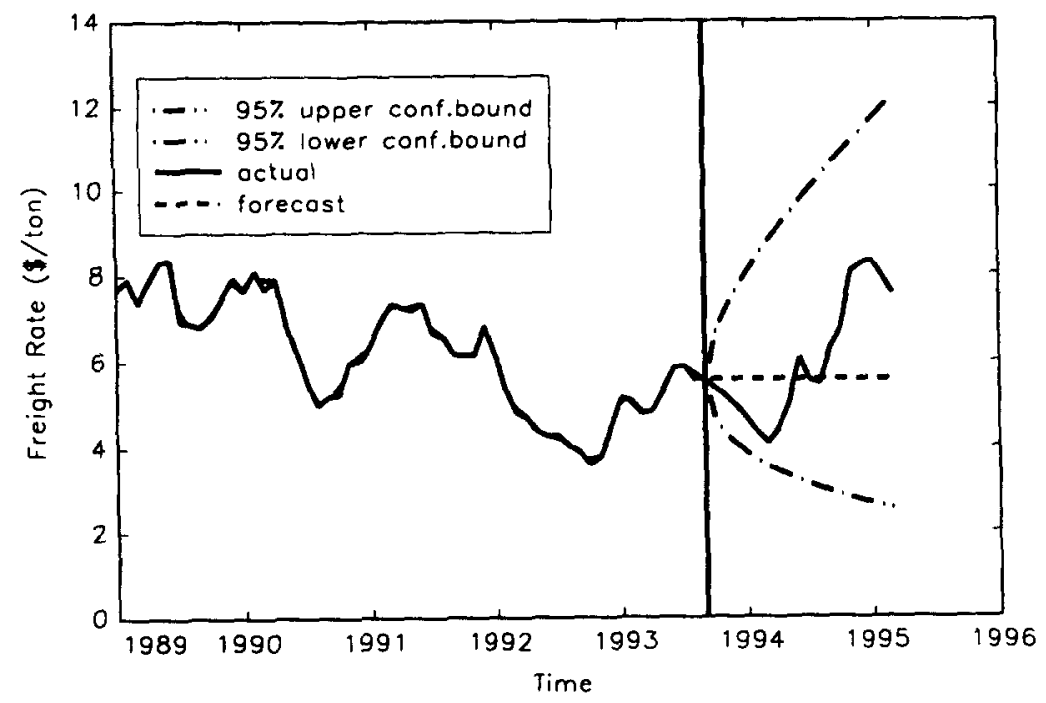

(b)

US Gulf-Rotterdom

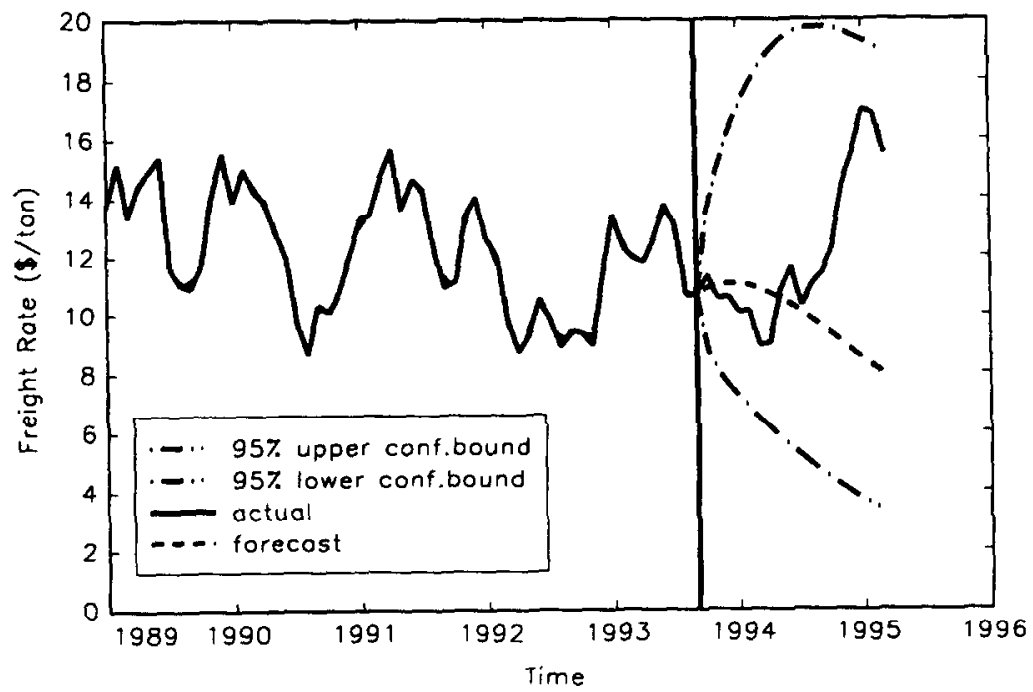

(c)

Hampton Roods-Rotterdom

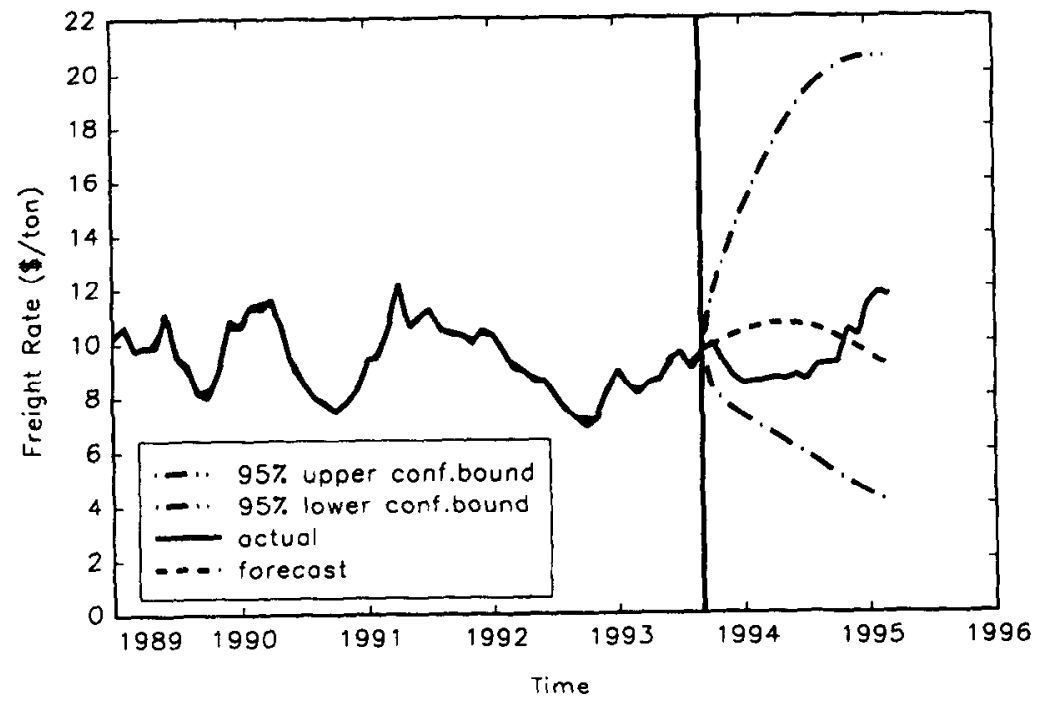

Fig. 5. Panamax series, forecasts and actual series. 
Table 7. Forecasting errors ${ }^{a}$

\begin{tabular}{|c|c|c|c|c|c|c|}
\hline & YICAP & Y2CAP & Y3CAP & Y4PAN & Y5PAN & Y6PAN \\
\hline \multicolumn{7}{|l|}{ Dynamic forecasts } \\
\hline \multicolumn{7}{|l|}{ Model } \\
\hline Absolute error & 0.493 & 0.348 & 0.221 & 0.198 & 0.254 & 0.155 \\
\hline Percentage error & 18.20 & 14.18 & 12.31 & 10.98 & 9.66 & 6.94 \\
\hline Mean squared error & 0.381 & 0.180 & 0.071 & 0.056 & 0.125 & 0.029 \\
\hline \multicolumn{7}{|l|}{ Naive method $b$} \\
\hline Absolute error & 0.177 & 0.186 & 0.211 & 0.198 & 0.161 & 0.101 \\
\hline Percentage error & 6.72 & 7.86 & 11.50 & 10.98 & 6.15 & 4.49 \\
\hline Mean squared error & 0.050 & 0.050 & 0.067 & 0.056 & 0.050 & 0.013 \\
\hline \multicolumn{7}{|l|}{$\begin{array}{l}\text { One-period forecasts } \\
\text { Model }\end{array}$} \\
\hline Absolute error & 0.084 & 0.104 & 0.088 & 0.073 & 0.068 & 0.046 \\
\hline Percentage error & 3.27 & 4.54 & 5.10 & 4.19 & 2.77 & 2.05 \\
\hline Mean squared error & 0.012 & 0.015 & 0.011 & 0.008 & 0.007 & 0.003 \\
\hline \multicolumn{7}{|l|}{ Naive method ${ }^{b}$} \\
\hline Absolute error & 0.062 & 0.074 & 0.087 & 0.073 & 0.072 & 0.035 \\
\hline Percentage error & 2.44 & 3.20 & 4.96 & 4.19 & 2.91 & 1.54 \\
\hline Mean squared error & 0.007 & 0.009 & 0.011 & 0.008 & 0.008 & 0.002 \\
\hline
\end{tabular}

The evaluation criteria employed are absolute forecast error, percentage error and mean squared error.

${ }^{b}$ The naive forecasting method uses the last known observation as a forecast.

Acknowledgements-We wish to thank Cliff Tyler for making available the freight rate data of Clarkson Research Studies Ltd. We are also grateful to the Editor-in-chief and to three anonymous referees for their extensive and very helpful comments. Franses thanks the Royal Netherlands Academy of Arts and Sciences for its financial support.

\section{REFERENCES}

Beenstock, M. and Vergottis, A. (1993) Econometric Modelling of World Shipping. Chapman and Hall, London.

Cullinane, K. P. B. (1992) A short-term adaptive forecasting model for BIFFEX speculation, a Box-Jenkins approach. Maritime Policy and Management 19, 91-114.

Dickey, D.A and Fuller, W. A. (1979) Distribution of estimators for autoregressive time series with a unit root. Journal of the American Statistical Society 74, 427-431.

Engle, R. F. and Granger, C. W. J. (1987) Co-integration and error correction: representation, estimation, and testing. Econometrica 55, 251-276.

Evans, J. J. (1994) An analysis of efficiency of the bulk shipping markets. Maritime Policy and Management 21, 311-329.

Fama, E. F. (1970) Efficient capital markets: a review of theory and empirical work. Journal of Finance 25, 383423.

Johansen, S. (1991) Estimation and hypothesis testing of cointegration vectors in Gaussian vector autoregressive models. Econometrica 59, 1551-1580.

Johansen, S (1991) Estimating systems of trending variables. Econometric Reviews 13, 351-386.

Hawdon, D. (1978) Tanker freight rates in the short and the long run. Applied Economics 10, 203-217.

MacKinnon, J. G. (1991) Critical values for cointegration tests. Long run economic relationships in cointegration (eds $R$. F. Engle, and C. W. J. Granger), Oxford University Press, Oxford.

Mills, T. C. (1990) Time Series Techniques for Economists, (reprint 1992). Cambridge University Press, Cambridge, United Kingdom.

Nicholson, W. (1989) Microeconomic Theory, 4th edn. The Dryden Press International, Chicago, Illinois.

Osterwald-Lenum, M. (1992) A note with quantiles of the asymptotic distribution of the maximum likelihood cointegration rank test statistics. Oxford Bulletin of Economics and Statistics 54, 461-471.

Strandeness, S. P. (1986) NORSHIP_a Simulation Model for Bulk Shipping Markets. World Market Prospects report no. 6. Norwegian School for Economics and Business Administration, Centre for applied research, Bergen, Norway. 